\title{
Estimating the size of the homeless adolescent population across seven cities in Cambodia
}

\author{
Lindsay Stark ${ }^{1 *}$, Beth L. Rubenstein ${ }^{1,2}$, Kimchoeun Pak ${ }^{3}$, Rosemary Taing ${ }^{4}$, Gary Yu ${ }^{5}$, Sok Kosal ${ }^{6}$
} and Leslie Roberts ${ }^{1}$

\begin{abstract}
Background: The Government of Cambodia has committed to supporting family care for vulnerable children, including homeless populations. Collecting baseline data on the numbers and characteristics of homeless adolescents was prioritized to illuminate the scope of the issue, mobilize resources and direct the response.

Methods: Administrative zones across seven cities were purposively selected to cover the main urban areas known to have homeless populations in Cambodia. A complete enumeration of homeless individuals between the ages of 13 and 17 was attempted in the selected areas. In addition, a second independent count was conducted to enable a statistical estimation of completeness based on overlap across counts. This technique is known as capture-recapture. Adolescents were also interviewed about their schooling, health and other circumstances.

Results: After adjustment by the capture-recapture corrective multipliers (range: 3.53 -27.08), the study yielded an estimate of 2,697 13-17 year old homeless adolescents across all seven cities. The total number of homeless boys counted was significantly greater than homeless girls, especially in older ages.

Conclusions: To the authors' knowledge, this is the first time capture-recapture methods have been applied to a homeless estimation of this scale in a resource-limited setting. Findings suggest the number of homeless adolescents in Cambodia is much greater than one would expect if relying on single count data alone and that this population faces many hardships.
\end{abstract}

Keywords: Homeless, Adolescents, Capture-recapture, Cambodia

\section{Background}

"Leave no one behind" is a central guiding principle of the post-2015 global development agenda. The international community is increasingly embracing the importance of inclusiveness and equity in policies and programming. However, actors are recognizing that the global monitoring framework lacks mechanisms to assess the most vulnerable and hard to reach populations [1]. For example, it is estimated that household surveys such as the Demographic and Health Survey (DHS) and the Multiple Indicator Cluster Survey (MICS) may overlook up to a quarter of the poorest wealth quintile [2]. Many of these

\footnotetext{
*Correspondence: Is2302@cumc.columbia.edu

'Department of Population and Family Health, Mailman School of Public Health, Columbia University, 60 Haven Avenue, New York, NY 10032, USA Full list of author information is available at the end of the article
}

missing millions are adolescents who are homeless or migrants living in improper housing, such as in construction sites or in urban slums.

Young people who lack a safe, stable and protective home face a multitude of adversities associated with extreme poverty. These adverse childhood experiences are linked to toxic levels of stress and impede proper physical, intellectual and emotional growth across the life course [3-5]. Scientific evidence about the specific impact of homelessness in childhood is limited, but some studies suggest that homeless adolescents have heightened risks, such as substance abuse, gang membership and commercial sex work, compared to adolescents living in homes [6-8]. Further, the disadvantages of childhood adversity persist with time. As children who experience adverse events in early life become 
adults, they are more likely to have poor health and limited productivity $[3,9]$.

Recently the Royal Government of Cambodia committed to investing in family strengthening initiatives and reducing the number of children outside of family care, including homeless populations. Before rolling out programs associated with this initiative, collecting baseline data on the numbers and characteristics of homeless children was needed to illuminate the scope of the issue, mobilize resources and direct the response.

This article describes the methodology and findings from an estimation of homeless adolescents in seven major cities in Cambodia led by the Cambodian National Institute of Statistics, Columbia University and Friends International, with support from Moulathan Consulting. Using a measurement technique known as capturerecapture, two independent counts were conducted on two different days in order to enable statistical estimates of completeness. A similar method was used in Brazil and Malawi to estimate the number of street children in select cities, but the definition of the target population was loosely defined and included children who worked on the street, yet slept in proper housing. Further, the Brazil and Malawi studies were limited to just one or two cities [10-12]. To the authors' knowledge, this is the first time capture-recapture methods have been applied to a homeless estimation of this scale in a resourcelimited setting.

\section{Methods}

\section{Sampling}

Fifteen administrative zones across seven cities were purposively selected to cover the main urban areas known to have young homeless populations, as determined by key informant interviews with local NGOs in the Cambodian Street Child Network and representatives from the Ministry of Social Affairs, Veterans and Youth Rehabilitation (MoSVY) (see Figure 1). NGO program data were also reviewed. In Phnom Penh, selection was done at the sangkat level (equivalent to boroughs) and elsewhere, selection was done at the district level (equivalent to counties). Within the selected zones, data collectors created maps to identify key sub-areas to visit and count adolescents. Within those sub-areas, data collectors attempted to enumerate all homeless 13-17 year olds.

\section{Inclusion criteria}

Enumeration of homeless children is complicated by the definition of homeless [13]. For example, individuals who sleep in a shelter made of plastic tarps may not selfidentify as homeless. Adolescents who work on the street to earn income on a daily basis are often mistakenly classified as street-living by observers. In this study, adolescents were classified as homeless if they were under 18 years of age and, during the week preceding data collection, they always or sometimes lived on the street, in emergency shelters or in public places, including construction sites (according to self-report). Adolescents living in dwellings with daily rent were included because the risk of eviction in these situations was extremely high. Adolescents were also classified as homeless if they slept in dwellings that did not offer approximately 3.5 square meters of covered space per person and did not provide basic protection from the elements [14]. Insufficient protection from the elements was operationalized to mean two or more walls

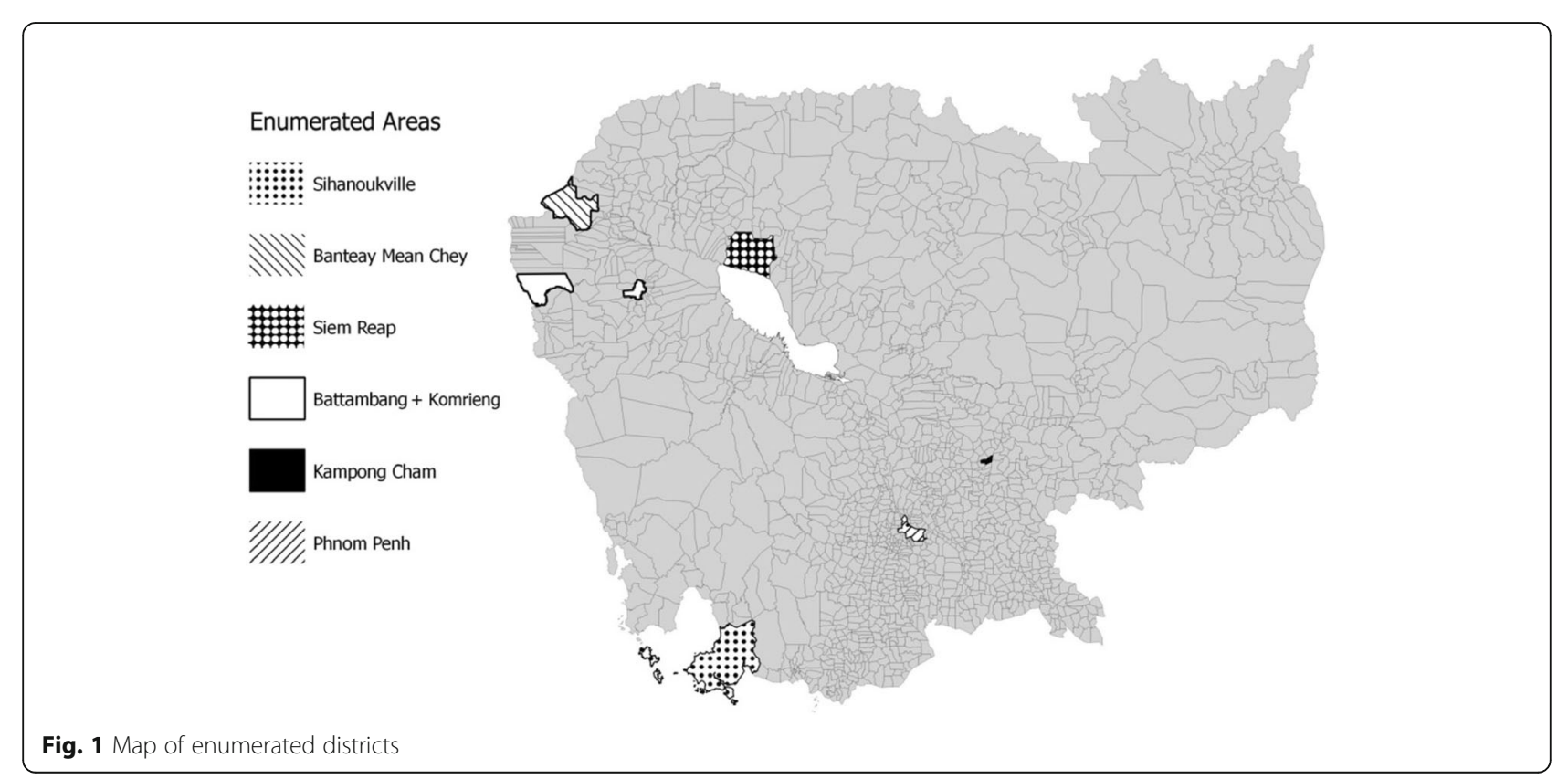


made out of makeshift plastic sheeting. Boat-living children were included based on the size of the living space and the adequacy of the construction, as previously defined [14].

The inclusion criteria were established based on international standards, field observations, and conversations with NGO outreach workers, government officials and the inter-agency technical working group guiding the project. Homeless status was based on the adequacy of adolescents' current living situation. Those adolescents who may have proper homes in rural areas, but who had migrated to cities, were therefore evaluated based on their current living situation in the city.

\section{Study design}

Two separate teams of enumerators conducted two independent counts of homeless 13-17 year olds in the key sub-areas of the selected administrative zones. The counts were conducted on two separate, full days, from morning through evening. Within these sub-areas, enumerators approached any young person thought to meet the age and inclusion criteria, introduced themselves and asked the young person to describe his/her housing situation. Those young people who were homeless and between the ages of 13 and 17 were then interviewed to gather identifying data, as well as information about their circumstances, including schooling, literacy, health, caregiver status and general well-being.

To avoid duplicate counting, all adolescents were shown a unique cartoon. If the adolescent told the enumerator that $\mathrm{s} / \mathrm{he}$ had already been shown the same cartoon earlier in the day, the individual was not counted again. Different cartoons were used on each day and adolescents counted on the second day were asked to recall the previous day's cartoon to facilitate the detection of overlap between the two counts. Identifying data (e.g., name, age, province of origin) were also used to detect overlap between the two counts. The study team used the overlap between the two independent counts to approximate the extent to which the first count may have missed individuals and create a corrective multiplier. This technique is known as capturerecapture (Stephen, 1996; Lum et al., 2013).

Data collection took place over four-weeks between August and September 2015. All data were collected electronically using the Field Task application for smart phones [15].

\section{Ethical considerations}

The team spent considerable time and effort designing protocols to protect the study participants. The minimum age of 13 years for respondents was selected based on extensive conversations with social workers in Cambodia who work with the target population and regularly observe children's decision-making skills. The minimum age of 13 years is also consistent with international recommendations, which state that adolescents' ability to meaningfully participate in the consent process is informed by their cultural and experiential context $[16,17]$.

To ensure confidentiality of the identifiable data, data were only accessible to research team leads on a password-protected server. All identifying information was deleted after matching was complete. Still, despite these precautions, there remained a small risk that confidentiality would be breached, hence the requirement of informed consent and the restriction against participation by children under 13 years of age.

All data collectors were hired through partnerships with local NGOs in the Cambodian Street Child Network and thus previously had substantial experience working with the target population. Data collectors gave a small snack to all children who were encountered, whether or not they consented to participate in the research. Ethical approval was obtained from the Institutional Review Board at Columbia University (AAAP2507) and the Cambodian National Ethics Committee.

\section{Statistical analysis}

Chi-squared tests and t-tests were used to compare the characteristics of adolescents across sex and age. For capture-recapture, the final estimate of adolescents not included in either list was calculated by multiplying the first count of adolescents by the second count of adolescents, and then dividing this product by the number of matched respondents. The total estimate is the sum of the adolescents in the first count, the adolescents in the second count, the adolescents in both counts and the adolescents not included in either list. All descriptive statistics were calculated using R [18] and SAS 9.4 [19].

For the purpose of this study, matching was achieved by comparing the following variables: family name, given name, nickname, sex, age, parents' names and province of origin. Duplicates and matches were identified through three techniques and searched across nearby districts or sangkats to allow for the possible movement of adolescents. First, the CRAN RecordLinkage package in $\mathrm{R}$ was used to match cases with weights greater than or equal to 0.80 , as determined by the package algorithm. (The algorithm examines the degree of differentiation provided by each response in an observation, and if that value matches a response for the same variable in another observation, the package adds the degree of differentiation between the two observations to the overall measure of matching, called a "weight.") Second, all remaining observations were manually reviewed to identify matches that the package did not detect. Most manually detected matches that were missed by the 
package were due to limitations faced by data collectors in transcribing Khmer names to the Roman alphabet during electronic data entry. Specifically, the CRAN RecordLinkage package struggled to find some phonetic similarities that were masked by different spellings. A Research Assistant who was bilingual in English and Khmer assisted with the manual matching processes. Third, observations from adolescents who were able to successfully recall the Day 1 cartoon on Day 2 were manually reviewed to identify additional matches.

\section{Results}

After capture-recapture adjustment, the study yielded an estimate of 2,697 homeless adolescents ages 13-17 across the seven cities where data collection was conducted. Across all areas combined, there were significantly more boys than girls counted $(64.32 \%$ versus $35.68 \%, p$-value $<0.0001)$. The mean age was 14.37 years overall. On average, boys were two and one-half months older than girls (14.45 years versus 14.24 years, $p$-value $<0.0671$ ) (see Table 2).

In eight out of nine areas where capture-recapture was performed, the capture-recapture estimate was five or more times larger than the number of young people enumerated during Count 1. In Siem Reap, where match rates were the lowest, the capture-recapture estimate was 27 times the number of young people enumerated during Count 1 (see Table 1). These findings suggest that the population of homeless adolescents is significantly larger than enumerators were able to document on either of the individual counts ${ }^{1}$.

Among the 569 homeless adolescents interviewed (response rate $=96.30 \%$ ), several patterns emerged (see Table 2). Almost all respondents reported having at least one parent alive. Furthermore, parents were reported to be the primary caregivers for $83.66 \%$ of respondents $(79.78 \%$ for males and $90.59 \%$ for females, $p$-value $=$ 0.0009), and most other respondents outside of parental care reported being cared for by other family members.
Very few adolescents reported having no adult caregiver (3.02\%), and all of the adolescents in this situation were male. Not having an adult caregiver was also more common amongst older adolescents (15-17 years), compared to younger adolescents (13-14 years) (5.06\% versus $1.53 \%, p$-value $=0.0157$ ).

About half of the respondents attended school on a daily basis, with girls attending school more regularly than boys $(p$-value $=0.0563)$. School attendance decreased as adolescents got older. Literacy was poor regardless of school attendance. Only about one third of the respondents could fully read the simple sentences presented to them, and one third of the respondents could not read at all. Again, girls' literacy was significantly better than boys' literacy ( $p$-value $=0.0076)$ (see Table 2).

In terms of work, $29.75 \%$ of respondents reported working five or more hours per day on five or more days per week. Older adolescents worked more compared to younger adolescents $(42.01 \%$ versus $20.86 \%, p$-value $<$ 0.0001 ), but did not differ significantly for boys compared to girls $(32.33 \%$ versus $25.26 \%, p$-value $=0.0896$ ) In contrast to work, only $6.60 \%$ of adolescents reported a heavy burden of chores (five or more hours per day on five or more days per week). The percent of adolescents doing this amount of chores did not differ by age or across boys and girls ( $p$-values $=0.8645$ and 0.1775 , respectively). One in four respondents reported that work or chores sometimes or always interfered with their schooling and nearly one in three reported that work or chores sometimes or always interfered with their sleep. Interference with schooling and sleep was significantly more common for boys, compared to girls $(p$-values $=0.0361$ and 0.0383 , respectively $)$.

In the 30 days prior to being interviewed, $13.14 \%$ of respondents reported being unable to work, study or do chores due to injury and $29.14 \%$ reported being unable to work, study or do chores due to illness. Rates of illness were similar between boys and girls, but rates of injury appear to be higher amongst boys compared to girls

Table 1 Numbers of children by province and district, 13-17 year olds (capture-recapture)

\begin{tabular}{|c|c|c|c|c|c|}
\hline Province & District/Sangkat & Count 1 & Count 2 & Matches & Total estimate \\
\hline Banteay Meanchey & Krong Poi Pet & 55 & 48 & 5 & 636 \\
\hline \multirow[t]{2}{*}{ Battambang } & Battambang & 19 & 16 & 2 & 189 \\
\hline & Komrieng & 11 & 20 & 3 & 107 \\
\hline Kampong Cham & Kampong Cham & 22 & 19 & 4 & 150 \\
\hline \multirow[t]{3}{*}{ Phnom Penh } & Chamkar Mon & 19 & 9 & 5 & 67 \\
\hline & Chbar Ampov & 52 & 39 & 10 & 304 \\
\hline & Doun Penh & 31 & 20 & 4 & 210 \\
\hline Preah Sihanouk & Preah Sihanouk & 49 & 25 & 4 & 384 \\
\hline Siem Reap & Siem Reap & 24 & 25 & 1 & 650 \\
\hline All areas & & 282 & 221 & 38 & 2,697 \\
\hline
\end{tabular}


Table 2 Child characteristics, $13-17$ year olds ( $n=569$, all districts)

\begin{tabular}{|c|c|c|c|c|}
\hline & All & Male & Female & $p$-value \\
\hline Sex & $100 \%$ & $64.32 \%$ & $35.68 \%$ & $<0.0001$ \\
\hline \multicolumn{5}{|l|}{ missing $=0$ children } \\
\hline \multicolumn{5}{|l|}{ Age } \\
\hline 13 years & $35.11 \%$ & $34.63 \%$ & $35.96 \%$ & \multirow[t]{5}{*}{0.1706} \\
\hline 14 years & $22.87 \%$ & $20.50 \%$ & $27.09 \%$ & \\
\hline 15 years & $21.81 \%$ & $21.88 \%$ & $21.67 \%$ & \\
\hline 16 years & $10.11 \%$ & $11.36 \%$ & $7.88 \%$ & \\
\hline 17 years & $10.11 \%$ & $11.63 \%$ & $7.39 \%$ & \\
\hline \multicolumn{5}{|l|}{ Missing $=5$ children } \\
\hline mean age, years (SD) & $14.37(1.32)$ & $14.45(1.37)$ & $14.24(1.23)$ & 0.0671 \\
\hline \multicolumn{5}{|l|}{ missing $=5$ children } \\
\hline \multicolumn{5}{|l|}{ parental status } \\
\hline both parents alive & $79.43 \%$ & $77.01 \%$ & $83.74 \%$ & \multirow[t]{6}{*}{0.3102} \\
\hline only mother alive & $14.36 \%$ & $15.79 \%$ & $11.82 \%$ & \\
\hline only father alive & $3.72 \%$ & $4.16 \%$ & $2.96 \%$ & \\
\hline both parents deceased & $2.13 \%$ & $2.77 \%$ & $0.99 \%$ & \\
\hline don't know & $0.35 \%$ & $0.28 \%$ & $0.49 \%$ & \\
\hline \multicolumn{4}{|l|}{ missing $=5$ children } & \\
\hline \multicolumn{5}{|l|}{ current caregiver } \\
\hline parent & $83.66 \%$ & $79.78 \%$ & 90.59 & \multirow[t]{7}{*}{0.0048} \\
\hline family member (not parent) & $9.59 \%$ & $10.53 \%$ & 7.92 & \\
\hline acquaintance & $1.95 \%$ & $2.49 \%$ & 0.99 & \\
\hline employer & $0.53 \%$ & $0.83 \%$ & 0.00 & \\
\hline other & $1.24 \%$ & $1.66 \%$ & 0.50 & \\
\hline no adult caregiver & $3.02 \%$ & $4.71 \%$ & 0.00 & \\
\hline \multicolumn{4}{|l|}{ missing $=6$ children } & \\
\hline \multicolumn{5}{|l|}{ school attendance } \\
\hline every day & $49.73 \%$ & $45.83 \%$ & $56.65 \%$ & \multirow[t]{5}{*}{0.0563} \\
\hline a few days a week & $9.59 \%$ & $10.00 \%$ & $8.87 \%$ & \\
\hline once in a while & $3.02 \%$ & $3.89 \%$ & $1.48 \%$ & \\
\hline never attend & $37.66 \%$ & $40.28 \%$ & $33.00 \%$ & \\
\hline \multicolumn{4}{|l|}{ missing $=6$ children } & \\
\hline \multicolumn{5}{|l|}{ literacy } \\
\hline able to read whole sentence & $32.19 \%$ & $27.25 \%$ & $40.84 \%$ & \multirow[t]{6}{*}{0.0076} \\
\hline able to read parts of sentence & $33.71 \%$ & $34.13 \%$ & $32.98 \%$ & \\
\hline cannot read at all & $33.33 \%$ & $37.43 \%$ & $26.18 \%$ & \\
\hline other & $0.19 \%$ & $0.30 \%$ & $0.00 \%$ & \\
\hline don't know & $0.57 \%$ & $0.90 \%$ & $0.00 \%$ & \\
\hline \multicolumn{4}{|l|}{ missing $=44$ children } & \\
\hline \multicolumn{5}{|l|}{ work } \\
\hline works 5 or more days per week and 5 or more hours per day & $29.75 \%$ & $32.33 \%$ & $25.26 \%$ & 0.0896 \\
\hline
\end{tabular}

missing $=48$ children

chores 
Table 2 Child characteristics, 13-17 year olds ( $n=569$, all districts) (Continued)

\begin{tabular}{|c|c|c|c|c|}
\hline \multicolumn{5}{|l|}{ missing $=54$ children } \\
\hline \multicolumn{5}{|l|}{ frequency that work/chores interfere with school } \\
\hline always & $8.25 \%$ & $10.73 \%$ & $3.89 \%$ & \multirow[t]{5}{*}{0.0361} \\
\hline sometimes & $16.90 \%$ & $16.40 \%$ & $17.78 \%$ & \\
\hline never & $68.41 \%$ & $65.62 \%$ & $73.33 \%$ & \\
\hline don't know & $6.44 \%$ & $7.26 \%$ & $5.00 \%$ & \\
\hline \multicolumn{4}{|l|}{ missing $=72$ children } & \\
\hline \multicolumn{5}{|l|}{ frequency that work/chores interfere with sleep } \\
\hline always & $8.00 \%$ & $9.28 \%$ & $5.76 \%$ & \multirow[t]{5}{*}{0.0383} \\
\hline sometimes & $23.43 \%$ & $26.35 \%$ & $18.32 \%$ & \\
\hline never & $67.05 \%$ & $62.57 \%$ & $74.87 \%$ & \\
\hline don't know & $1.52 \%$ & $1.80 \%$ & $1.05 \%$ & \\
\hline \multicolumn{4}{|l|}{ missing $=44$ children } & \\
\hline \multicolumn{5}{|l|}{ injured in the past 30 days (unable to work/study/do chores) } \\
\hline yes & $13.14 \%$ & $15.57 \%$ & $8.90 \%$ & 0.0910 \\
\hline \multicolumn{5}{|l|}{ missing $=44$ children } \\
\hline \multicolumn{5}{|l|}{ sick in the past 30 days (unable to work/study/do chores) } \\
\hline yes & $29.14 \%$ & $29.34 \%$ & $28.80 \%$ & 0.9785 \\
\hline \multicolumn{5}{|l|}{ missing $=44$ children } \\
\hline \multicolumn{5}{|l|}{ child feels safe where s/he lives } \\
\hline very safe & $44.57 \%$ & $43.71 \%$ & $46.07 \%$ & \multirow[t]{5}{*}{0.9225} \\
\hline somewhat safe & $44.19 \%$ & $44.91 \%$ & $42.93 \%$ & \\
\hline not at all safe & $10.48 \%$ & $10.48 \%$ & $10.47 \%$ & \\
\hline don't know & $0.76 \%$ & $0.90 \%$ & $0.52 \%$ & \\
\hline \multicolumn{4}{|l|}{ missing $=44$ children } & \\
\hline \multicolumn{5}{|l|}{ child trusts adults with whom s/he has contact } \\
\hline a lot & $48.57 \%$ & $47.60 \%$ & $50.26 \%$ & \multirow[t]{4}{*}{0.7620} \\
\hline somewhat & $41.14 \%$ & $42.51 \%$ & $38.74 \%$ & \\
\hline not at all & $8.38 \%$ & $7.78 \%$ & $9.42 \%$ & \\
\hline don't know & $1.90 \%$ & $2.10 \%$ & $1.57 \%$ & \\
\hline
\end{tabular}

$(15.57 \%$ versus $8.90 \%, p$-value $=0.0910)$. When asked to assess their sense of safety and trust, $10.48 \%$ of respondents said that they did not feel at all safe where they lived and $8.38 \%$ said that they did not have any trust in the adults with whom they interact. Older adolescents were significantly more likely to feel unsafe, compared to younger adolescents $(14.86 \%$ versus $7.26 \%, p$-value $=0.0049)$.

\section{Discussion}

\section{Strengths}

Globally, this is the first known study to attempt to apply a systematic and potentially reproducible method to simultaneously estimate young homeless populations in all the major urban areas within a country. Application of capture-recapture methods to the estimation of street children is relatively new. The research in Cambodia builds on recent work to estimate the population of street children in Brazil and Malawi using similar methods [10-12]. These findings, combined with the findings from Brazil and Malawi, demonstrate that capture-recapture can be feasibly carried out to measure young homeless populations in a range of settings.

An additional strength of this study is the use of clear inclusion criteria to define homelessness. Although the criteria diverge somewhat from commonly understood notions of street-living or street-working children, by focusing on young people's housing situations as opposed to their daily activities (e.g., panhandling), this study is able to better target those adolescents who are likely missed by household surveys [20-22]. Furthermore, the 
housing-related inclusion criteria also facilitated the recognition of new populations of vulnerable adolescents not previously known to NGOs working with street populations, such as those living on construction sites.

Finally, having NGO workers serve as enumerators was important to the success of the effort. Not only were the NGO workers familiar with the local geography, but they also were able to establish trust and rapport with adolescents and families, as reflected by the $96.30 \%$ response rate.

\section{Fidelity to capture-recapture assumptions}

The capture-recapture approach is not without limitations. First, capture-recapture assumes the population being counted is closed and that all members of the population can be matched if they appear in both counts. While key informants indicated that short-term movement in and out of the areas enumerated was low, there were likely at least a few children who entered or left the study area during the two-day data collection period. This movement would falsely inflate the estimates. In addition, there may have been some children who were counted twice but not identified as matches due to limitations in data quality or the computerized matching algorithm, which would also inflate the final estimates. The small sample size and single digit matches also affected the precision of the multipliers.

Second, capture-recapture assumes the lists being compared are independent (i.e., the biases within Count 1 and Count 2 are not related). While the use of outreach workers as enumerators was advantageous for the reasons described above, their involvement may have simultaneously undermined this assumption. Although enumerators were clearly instructed to cover areas beyond the places where they provide outreach services, a tendency to gravitate to familiar locations likely persisted. Moreover, it is likely that the areas where the enumerators gravitated were similar across counts, despite the fact that the teams were given strict guidance not to communicate their specific plans to their colleagues on other teams. These tendencies would falsely inflate the number of matches and lead to an underestimate of homeless children.

\section{Limitations}

Data were not collected from children below 13 years due to ethical considerations. The study therefore lacks insights into children under 13. Future research is needed to get an indicative sense of whether capturerecapture for children under 13 years of age would yield similar multipliers to the 13-17 year olds or if the ratio of counted to uncounted children varies by age group.

In addition, the study was limited by self-reported measurements of adolescent characteristics. Suspicion of authority may have influenced the validity of responses to certain questions, especially those concerning trust and safety. Finally, NGO partners reported that staffing limitations likely limited the thoroughness of the enumeration.

\section{Policy implications}

The study findings provide important information for practitioners and policymakers in Cambodia. Results suggest that the number of homeless children in Cambodia ages 13-17 is much greater than one would count in a single street census. In eight out of nine areas enumerated, Count 1 undercounted homelessness by a factor of five or more, indicating large numbers of vulnerable adolescents who are hidden from outreach workers and who may require social services. Conversations with partners confirmed that certain categories of adolescents covered by the study, such as those living on construction sites, were previously unknown to organizations and not currently receiving social services, despite apparent need.

More homeless boys were encountered than girls, especially in older ages. Further research is needed to understand what happens to homeless girls as they age and disappear from the population that was enumerated. The pathways and vulnerabilities faced by these uncounted girls, including in regard to sex work, require further illumination.

Overall, the interviews reflected the many hardships faced by homeless adolescents in Cambodia. Homeless adolescents often work long hours, are frequently injured, and do not get enough sleep. They are unable to pursue their education or attain basic literacy, and contend with frequent health problems that interfere with their day-to-day activities. An alarming number of adolescents do not feel safe or have relationships with any adults who they can trust. Still, despite these bleak circumstances, the vast majority of those interviewed said that they have a caregiver who is related to them, suggesting that one way to maximize the effectiveness of social services may be through family strengthening programs.

\section{Conclusion}

In developing robust approaches to monitor young populations currently invisible to the system, Cambodia has the opportunity to systematically recognize and reach many of the most vulnerable members of society. Investments in children have been shown to catalyze longlasting gains in families, communities and nations, but without inclusive data collection, these investments will not be appropriately targeted or evaluated [23, 24]. This study demonstrates that, with innovative methods, it is feasible to collect data on a hard to reach population. 
The findings are relevant to researchers, policymakers, practitioners and anyone committed to equitable social and economic development.

Endnotes

${ }^{1}$ Note that capture-recapture was not performed in districts with fewer than 25 children across both counts due to concerns about the precision of the match rate in such settings.

\section{Abbreviations}

DHS: Demographic and Health Survey; MICS: Multiple Indicator Cluster Survey; MoSVY: Ministry of Social Affairs, Veterans and Youth Rehabilitation

\section{Acknowledgements}

The authors wish to Rick Rinehart from the Global Alliance for Children, Sebastien Marot from Friends International, and David Whitford for his invaluable statistical advice.

\section{Funding}

Funding was provided by the U.S. Agency for International Development via John Snow International. The funding bodies had no role in the study design, collection, analysis or interpretation of the data, writing the article, or the decision to submit the article for publication.

\section{Availability of data}

Data cannot be shared because it is not authorized by the Institutional Review Board that approved this study.

\section{Authors' contributions}

LS, LR and BR led the conceptual design of the study. BR, KP, RT and SK facilitated fieldwork engagement and provided technical guidance on implementation. GY supported data analysis. LS and BR led preparation of the article and coordinated authors' inputs. All authors engaged in development of the final draft of the article. All authors read and approved the final article.

\section{Competing interests}

The authors declare that they have no competing interests.

\section{Consent for publication}

Not applicable.

\section{Ethics approval and consent to participate}

Ethical approval was obtained from the Institutional Review Board at Columbia University (AAAP2507) and the Cambodian National Ethics Committee. Children between the ages of 13-17 provided written consent to participate in the study.

\section{Author details}

${ }^{1}$ Department of Population and Family Health, Mailman School of Public Health, Columbia University, 60 Haven Avenue, New York, NY 10032, USA. ${ }^{2}$ Department of Epidemiology, Mailman School of Public Health, Columbia University, New York, USA. ${ }^{3}$ Moulathan Consulting, Phnom Penh, Cambodia. ${ }^{4}$ Friends International, Phnom Penh, Cambodia. ${ }^{5}$ New York University Rory Meyers College of Nursing, New York, USA. ${ }^{6}$ National Institute of Statistics, Ministry of Planning, Royal Government of Cambodia, Phnom Penh, Cambodia.

Received: 25 June 2016 Accepted: 16 January 2017

Published online: 26 January 2017

\section{References}

1. Clay R, CdeBaca L, De Cock KM, Goosby E, Guttmacher A, Jacobs S, Pablos-Mendez A, Polaski S, Sheldon G, Steinberg D. A call for coordinated and evidence-based action to protect children outside of family care. Lancet. 2012;379(9811):e6-8.

2. Carr-Hill R. Missing millions and measuring development progress. World Dev. 2013;46:30-44.
3. Anda RF, Felitti VJ, Bremner JD, Walker JD, Whitfield C, Perry BD, Dube SR, Giles WH. The enduring effects of abuse and related adverse experiences in childhood. Eur Arch Psychiatry Clin Neurosci. 2006;256(3):174-86.

4. Fierman AH, Dreyer BP, Quinn L, Shulman S, Courtlandt CD, Guzzo R. Growth delay in homeless children. Pediatrics. 1991;88(5):918-25.

5. Worthman CM, Panter-Brick C. Homeless street children in Nepal: use of allostatic load to assess the burden of childhood adversity. Dev Psychopathol. 2008;20(01):233-55.

6. Anarfi JK. Vulnerability to sexually transmitted disease: street children in Accra. Health Transit Rev. 1997;281-306.

7. Ayaya S, Esamai F. Health problems of street children in eldoret, Kenya. East Afr Med J. 2001;78(12):624-30.

8. Nada KH, El Daw AS. Violence, abuse, alcohol and drug use, and sexual behaviors in street children of greater Cairo and Alexandria, Egypt. Aids. 2010;24:S39-44.

9. Felitti VJ, Anda RF, Nordenberg D, Williamson DF, Spitz AM, Edwards V, Koss MP, Marks JS. Relationship of childhood abuse and household dysfunction to many of the leading causes of death in adults: the adverse childhood experiences (ACE) study. Am J Prev Med. 1998;14(4):245-58.

10. Making the Invisible Visible: An Enumeration of Children on the Streets in Malawi [https://www.human-dignity-foundation.org/wp-content/uploads/ 2016/01/Retrak-Making-the-invisible-visible-Malawi-Enumeration-2015.pdf]. Accessed 20 Mar 2016.

11. Gurgel R, Da Fonseca J, Neyra-Castaneda D, Gill G, Cuevas L. Capture-recapture to estimate the number of street children in a city in brazil. Arch Dis Child. 2004;89(3):222-4.

12. Bezerra KF, Gurgel RQ, llozue C, Castaneda DN. Estimating the number of street children and adolescents in two cities of brazil using capture-recapture. J Paediatr Child Health. 2011;47(8):524-9.

13. Hillis SD, Zapata L, Robbins CL, Kissin DM, Skipalska H, Yorick R, Finnerty E, Marchbanks PA, Jamieson DJ. HIV seroprevalence among orphaned and homeless youth: no place like home. Aids. 2012;26(1):105-10.

14. The Sphere Handbook: Humanitarian Charter and Minimum Standards in Humanitarian Response [ http://www.spherehandbook.org/ ]. Accessed 20 Mar 2016.

15. Penman N. Field Task. Canberra, Australia: SMAP Consulting; 2015

16. Alderson P. Competent children? Minors' consent to health care treatment and research. Soc Sci Med. 2007;65(11):2272-83.

17. Petersen AC, Leffert N. Developmental issues influencing guidelines for adolescent health research: a review. J Adolesc Health. 1995;17(5):298-305.

18. R: A language and environment for statistical computing [http://www.Rproject.org/]

19. SAS Institute Inc.: SAS Institute Version 9.4. Cary, NC: SAS Institute Inc.; 2013.

20. Aptekar L. Street children in the developing world: a review of their condition. Cross-Cult Res. 1994;28(3):195-224.

21. Glauser B. Street children: Deconstructing a construct. In: James A, Prout A, editors. Constructing and reconstructing childhood: Contemporary issues in the sociological study of childhood. London: Falmer Press; 1997. p. 145-164.

22. Lalor KJ. Street children: a comparative perspective. Child Abuse Negl. 1999; 23(8):759-70.

23. Engle PL, Black MM, Behrman JR. Cabral de Mello M, gertler PJ, kapiriri L, martorell $R$, young ME: strategies to avoid the loss of developmental potential in more than 200 million children in the developing world. Lancet. 2007;369(9557):229-42.

24. Irwin LG, Siddiqi A, Hertzman C. Early child development: a powerful equalizer. Geneva: Final report to the WHO Commission on Social Determinants of Health; 2007. 